Cambiemos: una política de nacionalidad electoral Mariano Cicowiez

Boletín de Arte (N. ${ }^{\circ}$ 19), e014, septiembre 2019. ISSN 2314-2502

https://doi.org/10.24215/23142502e014

http://papelcosido.fba.unlp.edu.ar/ojs/index.php/boa

Facultad de Bellas Artes. Universidad Nacional de La Plata

La Plata. Buenos Aires. Argentina

\title{
CAMBIEMOS: UNA POLÍTICA DE NACIONALIDAD ELECTORAL
}

\section{CAMBIEMOS COALITION: ELECTORAL NATIONALITY POLITICS}

\section{Mariano Cicowiez}

marianocicowiez@yahoo.com.ar

Consejo Nacional de Investigaciones Científicas y Técnicas (CONICET). Instituto de Historia del Arte Argentino y Americano. Facultad de Bellas Artes. Universidad Nacional de La Plata. Argentina

RESUMEN

La fuerza política Cambiemos dispuso, en la campaña presidencial realizada en 2015, una serie de imágenes constituidas por cuerpos políticos y civiles, espacios privados y objetos de uso cotidiano, en calidad de signos de la nacionalidad argentina contemporánea. Su representación visual / audiovisual ha atravesado el conjunto de los dispositivos de propaganda de la coalición gobernante. Aquí se propone analizar algunas muestras difundidas en medios masivos de comunicación.

Palabras clave

Cambiemos; campaña electoral; imágenes; nacionalidad

\section{ABstract}

Cambiemos political coalition presented, during the presidential campaign conducted in 2015 a series of images formed by political and civil bodies, private spaces and everyday use objects, as signs of the contemporary Argentine nationality. Its visual / audiovisual representation has gone through the whole group of propaganda devices used by the ruling coalition. Here we propose to analyze that matter through examples disseminated by the mass media.

\section{KEYWORDS}

Cambiemos; electoral campaign; images; nationality 
El examen de la estructura iterativa de las imágenes técnicas pertenecientes a una campaña de elección presidencial concierne, como ejemplo, a la representación de la nacionalidad que prevalece en dispositivos de carácter visual y audiovisual. Debido a que las acciones de propaganda política comprenden una planificación integral que se formaliza, de modo general, sobre el territorio federal de la nación, resulta oportuno indagar las características que asume la nacionalidad en calidad de signo semiótico, puesto al servicio de su instalación en el debate que suscita una contienda electoral. ${ }^{1}$

La campaña ejecutiva 2015 perteneciente a la coalición Cambiemos ha concitado menores atenciones con relación al esquema narrativo adjudicado al diseño de la imagen técnica, que con respecto al privilegio que sí adquirieron los pronunciamientos verbales de sus principales candidatos. La asociación que vincula los elementos visuales que han compuesto a las fotografías y a los spots televisivos no ha sido objeto de indagaciones teóricas y críticas en la misma proporción que, por caso, los anuncios orales de corte electoral. Es en este sentido que se propone analizar la estructura visual de la nacionalidad en las unidades focales citadas, con objeto de reconocer una serie de regularidades que sellaron su estilo de composición. ${ }^{2}$

Al respecto, Peter Burke (2005) asegura que «el nacionalismo resulta relativamente fácil de expresar en imágenes [...]. [Se puede representar mediante] el paisaje característico de la región» (pp. 82-83). En este proceso, se examinará la representación visual del ser nacional argentino sujeta a los propósitos de la campaña de Cambiemos.

\section{ABSTRACCIONES, CIRCUNSTANCIAS Y EMOCIONES}

La votación presidencial argentina 2015 comportó tres instancias de sufragio: las denominadas Primarias, abiertas, simultáneas y obligatorias (PASO), realizadas el 9 de agosto; la primera vuelta electoral, el 25 de octubre; y la segunda vuelta o balotaje, el 22 de noviembre. En ellas se implementaron etapas sucesivas de funcionamiento de los ejes que modulan una campaña electoral. ${ }^{3}$ No obstante, en la contienda ha prevalecido una gramática de producción acerca de la norma en razón de la cual la nacionalidad argentina ha sido asumida por la fuerza política hoy gobernante, como asimismo de sus modos de representación visual y audiovisual. Es decir que la representación concierne primero a una elección de aquellos aspectos o circunstancias que comprometen la nacionalidad y que, en una segunda instancia, intervienen en la conformación de la diégesis de las imágenes de uso proselitista.

En cuanto a la elección de un acopio de simbologías que, debido a una convención - como es natural-, remiten a la nacionalidad, Cambiemos ha desarrollado al menos tres circunstancias posibles de asimilar, de modo respectivo, a los cuerpos, a los objetos y a los espacios que integraron las fotografías y los avisos audiovisuales. La reducción necesaria que de ellas se efectuó para su inclusión en una imagen técnica resulta proporcional, en efecto, al traspaso de un concepto a un objeto visible que lo representa o alude en una condición. En este sentido, Giovanni Sartori (2003) señala:

\footnotetext{
1 En este artículo se examina la instancia de producción de una serie de piezas de comunicación. El análisis acerca de sus efectos corresponde a un estudio semejante al que aquí se presenta, completando, de este modo, el reconocimiento de la circulación de las unidades focales seleccionadas.

2 El método de estudio incluye la parada de la imagen fílmica (Aumont \& Marie, 1993), en razón de las limitaciones de diagramación naturales a un artículo de estas características.

3 Jaime Durán Barba y Santiago Nieto (2017a), señalan que una estrategia electoral se compone de las etapas siguientes: reconocimiento de la imagen del candidato, de sus oponentes y de los partidos a los cuales adhieren; examen de las fortalezas y debilidades de los aspirantes; establecimiento de temas para determinar los posicionamientos; detección de votantes hipotéticos y creación de mensajes para alcanzarlos y obtener consentimiento electoral. En este sentido, los ejes que atraviesan una contienda varían en razón de los intereses de los adversarios que los instalan.
} 
La imagen es enemiga de la abstracción, mientras que explicar es desarrollar un discurso abstracto. Ya he dicho en otras ocasiones que los problemas no son «visibles». Lo que podemos ver en la televisión es lo que «mueve» los sentimientos y las emociones (p. 43).

Por lo tanto si la nacionalidad no es posible de representar sino a través de algunos de sus aspectos, en los casos que aquí se examinan las características de estos se hallaron sujetas a las emociones que suscitan los encuentros familiares, en horas de descanso y en el interior de una vivienda, o los emprendimientos comerciales privados.

\section{ACERCA DE LOS OBJETOS}

En las unidades focales seleccionadas se reiteró la inclusión de una serie de objetos comúnmente asociados al ser nacional argentino. Entre ellos, se destaca un equipo de mate y termo de agua, ubicado en posición central con respecto a los cuerpos políticos y civiles que lo circundan [Figura 1]. La composición de las imágenes realza estos objetos inmediatamente reconocibles por parte del espectador, y que atraviesan a las competencias de sus distintas segmentaciones. Es en este sentido que el motivo mate y su actualización, en este caso, en calidad de nacionalidad argentino - que confiere unidad temática a la estructura de las imágenes-, se reduce en la instancia de reconocimiento de la superficie textual concebida por los órganos de comunicación de Cambiemos. ${ }^{4}$

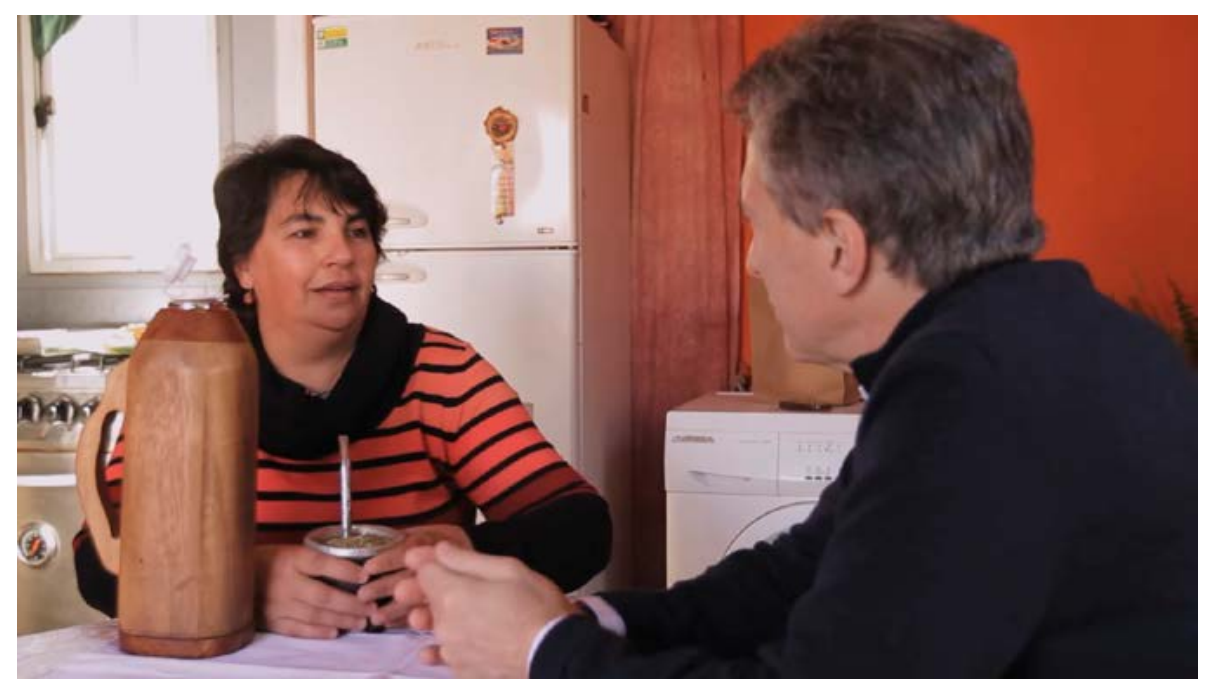

Figura 1. Prensa Pro, Con Estela en Concordia [Fotograma] (2015a)

El recurso ficcional consiste en la producción de una conexión no dinámica surgida no a partir de una semejanza o una existencia, sino de una ley o una convención. Al respecto, Charles S. Peirce (1974) asevera que «un Símbolo es un signo que se refiere al objeto que denota en virtud de una ley, usualmente una asociación de ideas generales que operan de modo tal que son la causa de que el símbolo se interprete como referido a dicho Objeto» (p. 30). ${ }^{5}$ La relación que opera entre los extremos de producción y de reconocimiento se formalizó sobre una marca del texto, en este caso, un mate y su termo correspondiente, la cual presenta condiciones prontamente vinculadas al ser nacional. Esta conexión se sustentó en una convención que asume al mate como uno de los elementos que vivifican la cultura raigal de la Argentina, lo cual connota a la pieza audiovisual. Al respecto, Jean Mitry [1963] (2006) ha realizado un estudio exhaustivo acerca de la incorporación de elementos, al parecer irresolutos, en la puesta en escena, los cuales, asegura el autor, continuamente aportan información al compendio de la trama narrativa.

4 El estudio de las causas que remiten a la yerba mate como simbología argentina excede a los objetivos de esta publicación, por lo que el análisis de las imágenes se inicia a partir de dicho reconocimiento. 5 Parágrafo 249. La letra itálica pertenece al texto original. 
En efecto, el mate es un objeto cultural sobre el cual los argentinos reactualizan sus encuentros, afirmando al mismo tiempo su grado de igualdad y pertenencia. En las producciones de campaña de Cambiemos se replica la exhibición de este símbolo de la nacionalidad, formando sistema con los espacios y los cuerpos que completan la composición de las fotografías y de los anuncios audiovisuales.

\section{ACERCA DE LOS ESPACIOS}

Los espacios representados en las imágenes electorales también exhiben marcas acerca del sujeto de su enunciación, que remiten, como ejemplo, a la regla comunicacional que concibió el aspecto o circunstancia de la nacionalidad que debían reflejar los dispositivos tecnológicos. Debido a que «el lugar escogido no es allí en donde está a punto de suceder algo, sino en donde serán narrados cierto número de acontecimientos» (Berger, 1998, p. 62) el estudio de los espacios resulta consustancial. En este sentido, una de las principales condiciones de los espacios escogidos para desarrollar el esquema narrativo ha sido su carácter privado. En mayor medida los lugares en los que se compuso la puesta en escena de las imágenes de propaganda pertenecientes a Cambiemos han sido domicilios particulares y emprendimientos de trabajo no estatales. Entre los primeros se destacan los sitios de cocinas, comedores, vanos de acceso y patios internos. De los segundos prevalecen modestos locales comerciales de atención al público y ventas minoristas. En una y otra representación, se corresponden con espacios reducidos, mobiliarios utilitarios desprovistos de ostentación y con la vana apariencia de no haber sido intervenidos por los equipos de comunicaciones oficiales [Figura 2].

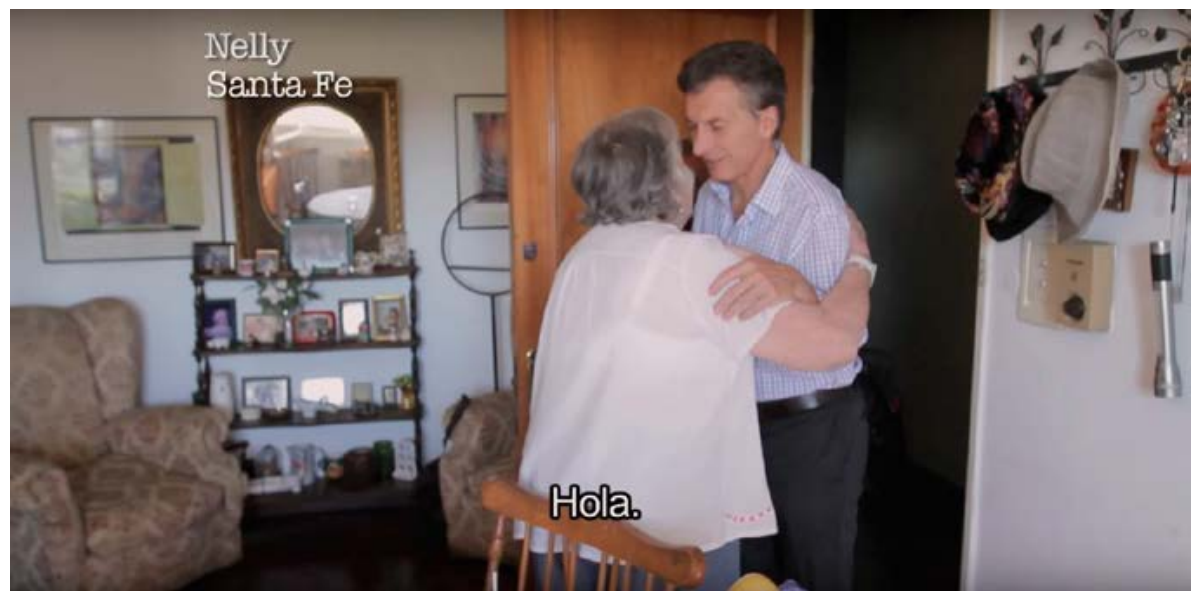

Figura 2. Prensa Pro, Con Nelly en Sonto Fe [Fotograma] (2015b)

La nacionalidad no se transparentó en los espacios habituales de la política argentina contemporánea. Al respecto, Silvio Waisbord (1995) señala el traspaso de actos de gobierno históricamente celebrados, por ejemplo, en Plaza de Mayo, hacia sitios urbanos que carecen de una memoria e identidad colectivas. Si en aquellos las acciones partidarias reactualizaban hechos de un tiempo pasado, en estos, por el contrario, la presencia de los candidatos restituye la centralidad que tales espacios adquieren para quienes a diario los transitan. En otros términos, el espacio público en carácter de escenario de acontecimientos de relevancia histórica, en el cual —solo a modo de mención, debido a que excede el orden de este artículo - tuvieron su bautismo de fuego movilizaciones que culminaron en el nacimiento de dos de las principales fuerzas políticas argentinas (1890, Revolución del Parque, Unión Cívica Radical; 1945, 17 de octubre, Partido Justicialista), no ha sido mayormente objeto de escenificaciones en las piezas de propaganda de Cambiemos. En cierto número de imágenes se representó una arteria lateral o un sitio abierto poco concurrido, en oposición a los registros visuales de las mayores concentraciones que tuvieron lugar en las últimas décadas de historia argentina. 
Por el contrario, los espacios privilegiados para representar la nacionalidad han sido de orden privado, en los cuales se reseñó el esfuerzo y la memoria individuales en perjuicio del trabajo y la unión colectivos. El ser nacional se correspondió con afectos personales y logros privados, al tiempo que se omitió una biografía histórica que los incluyese.

\section{ACERCA DE LOS CUERPOS}

Los cuerpos que intervinieron en las imágenes de Cambiemos pertenecen a las sociedades política y civil. En proporción a la primera sociedad, en mayor medida la componen Mauricio Macri y Gabriela Michetti, que integraron la fórmula presidencial, y María Eugenia Vidal, por entonces candidata a gobernadora de la provincia de Buenos Aires. Con respecto a la segunda sociedad, se ha privilegiado al núcleo familiar, representado en un número significativamente mayor que el segmento trabajador, que de manera ocasional se incluyó en las unidades de observación. En efecto, el perfil laboral de los ciudadanos ha cobrado protagonismo en los avisos que, sin embargo, no alcanzó a corresponder a los esquemas narrativos favorecidos por la inclusión del ámbito de la familia. Se ha testeado que, en las tres instancias de sufragio, ha sido este y no aquel el motivo que prevaleció en el conjunto de las piezas de propaganda.

El cuerpo político se representó apartidario (Durán Barba \& Nieto, 2017b) en correlación con una serie de prácticas comunes que desarrollaron las fuerzas históricas de gobierno argentino. El modelo de un líder que se apropia del uso de la palabra y una orden de adherentes que en mayor medida las escucha, ha sido revertido por una sociedad civil que pronuncia halagos y demandas, y un cuerpo presidencial que las acusa y las contiene [Figura 3].

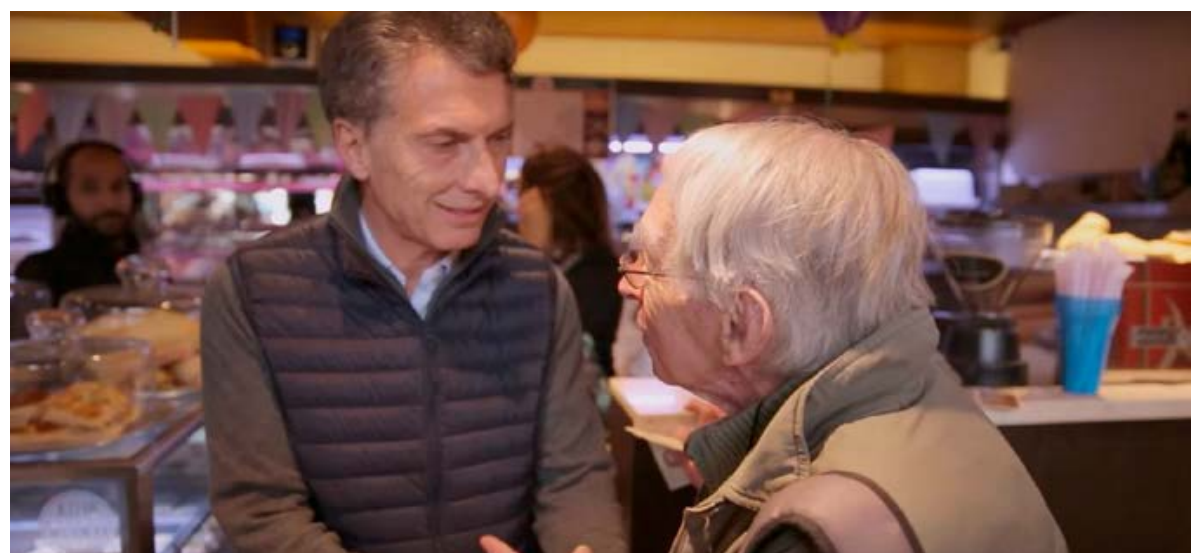

Figura 3. Prensa Pro, Cuidar a los maestros. Ese es mi compromiso [Fotograma] (2015c)

La imagen de Macri reduce las distancias habituales en relación con el significado que operan los movimientos de su cuerpo, debido a que «lo político comienza a significar el territorio inmediato, se juega en el micro-intercambio, solicita la decodificación del cuerpo significante» (Verón, 2001, p. 40). En este sentido, la inclusión de los votantes de Cambiemos en sus imágenes electorales restituyó la regla, hasta entonces vigente, acerca de la potestad que los partidos políticos ostentaron sobre la clase ciudadana. Ha sido esta, y ya no aquellos, el agente que reactualizó una nacionalidad que recusa a los partidos tradicionales de gobierno, en conjunto con sus insignias y elementos culturalmente acostumbrados.

En un informe de caso, Jacques Gerstlé (1998) clasifica a los spots audiovisuales proselitistas de acuerdo a dos categorías temáticas: una remite a la inclusión de posiciones generales y políticamente correctas, y la otra concierne a «la pertenencia a grupos y a la comunidad nacional» (p. 233). Cambiemos ha desarrollado spots en los cuales explicitó las propuestas de su hipotético ejercicio de gobierno y, asimismo, difundió propagandas que dieron cuenta, por ejemplo, del ser nacional a partir del cual aquellas fueron pronunciadas. Las figuras 1 y 2 aquí analizadas pertenecen a la segunda clasificación, mientras que la figura 3 se ubica entre ambas 
categorías. En esta última pieza, denominada Cuidar a los moestros. Ese es mi compromiso, la preponderancia de la estructura significante recayó sobre la voz de los candidatos y sobre los paratextos lingüísticos impresos sobre la pantalla, los cuales remiten a las dos situaciones establecidas por Gerstlé. En efecto, el aspirante de Cambiemos afirma que «porque son el ejemplo para los chicos, todos los maestros van a ser respetados, cuidados y bien remunerados. Ese es mi compromiso. Vamos juntos» (Prensa Pro, 2015c). Los textos sobreimpresos en la pantalla se establecen con la leyenda moestros respetodos, cuidados y bien remunerados. A través de la apelación al colectivo moestros, Cambiemos define una posición frecuente, al mismo tiempo que define un segmento trabajador de orden nacional.

\section{CONSIDERACIONES FINALES}

Los dispositivos de propaganda examinados han sido difundidos en todo el territorio argentino, a través de los principales medios masivos de comunicación de alcance federal. No se han tenido en cuenta las producciones proselitistas de orden local y regional, por lo que el estudio de las imágenes/muestras seleccionadas impacta en la observación de regularidades que atravesaron la construcción del ser nacional argentino contemporáneo. En tal sentido, los cuerpos, los objetos y los espacios pertenecientes a las unidades focales constituyeron materialidades significantes que debían exponer una norma posible de circular en diferentes contextos de recepción. Por ejemplo, los objetos y los espacios urbanos no presentaron condiciones excluyentes de una precisa geografía argentina, sino las características comunes al territorio de la Nación. Por su parte, los cuerpos civiles hicieron uso de un lenguaje y de una acentuación difícilmente identificable con los modismos de una región particular. De modo que la propaganda política ilustró la correspondencia entre los tres principios de composición, definiendo un modelo de síntesis difundido en las etapas electorales.

La afinidad entre las prácticas políticas y los medios de comunicación audiovisuales ha sido analizada por los politólogos Luis Alberto Quevedo (1992) y Oscar Landi (1992), quienes, respectivamente, sostienen:

Los medios y en especial la televisión le imprimen a la mediación política características inéditas que la desligan de las tradiciones de la cultura letrada para ingresar en zonas culturales que están ligadas a la imagen, a lo corporal, a los elementos de la vida cotidiana, al humor y al melodrama (Quevedo, 1992, p. 20).

Desde un punto de vista institucional, la importancia que vaya adquiriendo la videopolítica está en relación directa, privilegiada, con las características de los partidos políticos en cada país. En ausencia de un razonable grado de institucionalización de los mismos, con poco perfil e influencia ideológica sobre la sociedad, ante débiles lealtades partidarias y pocos votantes cautivos, se genera un espacio abierto en el que el poder del video se extiende con pocos contrapoderes a la vista. Desde este ángulo, lo que estaría en juego es la misma estructura y las formas de la acción política (Landi, 1992, p. 72).

La cultura visual ha atravesado su campo de pertenencia para constituirse en un dispositivo que determina un horizonte de acciones originariamente ajeno a su propia esfera de operación (Lipovetsky \& Serroy, 2015). Esta modificación de su estatuto ha sido oportunamente advertida por los equipos de comunicación, entre otros, de la coalición Cambiemos, y puesta al servicio de los actos proselitistas instituidos en el conjunto de la campaña 2015 argentina.

Las fotografías y las piezas audiovisuales han sido objeto de menores recusaciones como sí lo fueron los pronunciamientos, ocultamientos y omisiones verbales de la fuerza política actualmente en ejercicio. En el proceso analizado, el estudio de la representación visual de la nacionalidad puede desagregarse en los objetos, los cuerpos y los espacios que concitaron la estructura iterativa de las unidades focales de observación. 
En suma, la nacionalidad argentina ha sido representada de acuerdo a una serie de 1) objetos de uso cotidiano asociados al esparcimiento, 2) espacios representativos del esfuerzo individual y 3) cuerpos políticos apartidarios y cuerpos civiles en estado de ociosidad.

\section{REFERENCIAS}

Aumont, J. y Marie, M. (1993). Análisis del film. Barcelona, España: Paidós.

Berger, J. (1998). Mirar. Ciudad Autónoma de Buenos Aires, Argentina: Ediciones de la Flor.

Burke, P. (2005). Visto y no visto. El uso de la imagen como documento histórico. Barcelona, España: Crítica.

Durán Barba, J. y Nieto, S. (2017a). El arte de ganar. Cómo usar el atoque en compañas electorales exitosas. Ciudad Autónoma de Buenos Aires, Argentina: Debate.

Durán Barba, J. y Nieto, S. (2017b). Lo política en el siglo XXI. Arte, mito o ciencio. Ciudad Autónoma de Buenos Aires, Argentina: Debate.

Gerstlé, J. (1998). El nuevo espacio público. Barcelona, España: Gedisa.

Landi, 0. (1992). Devórame otra vez. ¿Qué hizo la televisión con la gente? ¿Qué hace la gente con la televisión? Ciudad Autónoma de Buenos Aires, Argentina: Planeta.

Lipovetsky, G. y Serroy, J. (2015). Lo estetización del mundo. Vivir en lo époco del copitalismo artístico. Ciudad Autónoma de Buenos Aires, Argentina: Anagrama.

Mitry, J. [1963] (2006). Estética y psicología del cine. 1 Las estructuras. Ciudad de México, México: Siglo Veintiuno.

Peirce, Ch. S. (1974). La ciencio de la semiótica. Ciudad Autónoma de Buenos Aires, Argentina: Nueva Visión.

Prensa Pro. (2015a). Con Estela en Concordio [Archivo de video]. Disponible en https://youtu. be/MkEdN5ynM_l?list=PLAr8GMNsEX37bqm1Y8TMFpt-xrqLZ8kTo

Prensa Pro. (2015b). Con Nelly en Santo Fe [Archivo de video]. Disponible en https://youtu. be/f1b0apeDm58?list=PLAr8GMNsEX37bqm1Y8TMFpt-xrqLZ8kTo

Prensa Pro. (2015c). Cuidar a los moestros. Ese es mi compromiso [Archivo de video]. Disponible en https://youtu.be/fai91Ax0Ta4?list=PLAr8GMNsEX37G3D5J 6Rd5 CeFj Q S O K WyBl

Quevedo, L. A. (1992). La política bajo el formato televisivo. En H. Schmucler y M. C. Mata (Comps.), Política y comunicación. ¿Hay un lugar para la política en la cultura mediática? (pp. 13-20). Ciudad Autónoma de Buenos Aires, Argentina: Catálogo.

Sartori, G. (2003). Homo Videns. Ciudad de México, México: Octaedro.

Verón, E. (2001). El cuerpo de las imágenes. Bogotá, Colombia: Grupo Editorial Norma.

Waisbord, S. (1995). El gran desfile. Compañas electorales y medios de comunicación en la Argentina. Ciudad Autónoma de Buenos Aires, Argentina: Sudamericana. 